University of Nebraska - Lincoln

DigitalCommons@University of Nebraska - Lincoln

Sociology Department, Faculty Publications

Sociology, Department of

2004

\title{
Victims and Offenders: Accounts of Paybacks, Invulnerability, and Financial Gain among Homeless Youth
}

Kimberly A. Tyler

University of Nebraska-Lincoln, kim@ktresearch.net

Katherine Johnson

University of Nebraska-Lincoln

Follow this and additional works at: https://digitalcommons.unl.edu/sociologyfacpub

Part of the Sociology Commons

Tyler, Kimberly A. and Johnson, Katherine, "Victims and Offenders: Accounts of Paybacks, Invulnerability, and Financial Gain among Homeless Youth" (2004). Sociology Department, Faculty Publications. 59.

https://digitalcommons.unl.edu/sociologyfacpub/59

This Article is brought to you for free and open access by the Sociology, Department of at DigitalCommons@University of Nebraska - Lincoln. It has been accepted for inclusion in Sociology Department, Faculty Publications by an authorized administrator of DigitalCommons@University of Nebraska - Lincoln. 
Published in Deviant Behavior, 25:5 (2004), pages 427-449;

doi 10.1080/01639620490468561 Copyright () 2004 Taylor \& Francis Inc.

Used by permission. http://www.tandf.co.uk/journals/tf/01639625.html

Submitted June 23, 2003; accepted April 2, 2004.

\title{
Victims and Offenders:
}

Accounts of Paybacks,

Invulnerability, and Financial

Gain among Homeless Youth

\author{
Kimberly A. Tyler \& Katherine A. Johnson \\ University of Nebraska-Lincoln, Lincoln, Nebraska, USA
}

\begin{abstract}
Previous research has suggested that "victim" and "offender" are not mutually exclusive categories but rather represent a homogeneous pool in which offenders are victimized and victims also offend. Little is known, however, about the specifics of the victim and offender process. The current study formally addresses the following research questions: why are some individuals at higher risk for victimization compared to others; why do some young people offend while others do not; and finally, why are criminal victims likely to retaliate? Given that homeless young people generally have high rates of offending and are also exceedingly vulnerable to crime, they represent an ideal sample for examining this process. The purpose of this investigation is to examine, in depth, the victimization and offending experiences of 40 homeless males and females in the Midwest and to place such experiences in a larger context by including an examination of both their early life histories and their current street exposure.
\end{abstract}

Research reported in this article was funded by a UNL Faculty Seed Grant awarded to the first author and by the National Institute of Mental Health (MH 57110).

Correspondence - Kimberly A. Tyler, kim@ktresearch.net 
Although some researchers contend that "victim" and "offender" are not mutually exclusive categories but rather represent a homogeneous pool in which offenders are victimized and victims also offend (Hindelang et al. 1978; Kennedy and Baron 1993; Lauritsen et al. 1991), much of the literature concerning victims and/or offenders does not specifically research this overlap, particularly among homeless youth. Those studies that do exist have typically focused either on the victimization (cf. Gary and Campbell 1998; Kipke et al. 1997; Tyler et al. 2001a), or on the offending behaviors of homeless youth (Baron and Kennedy 1998; McCarthy and Hagan 1991). Further, there is an absence of qualitative research on the dyadic nature of victims and offenders among homeless youth (cf. Kennedy and Baron 1993 for a notable exception) and even though a handful of studies have focused specifically on this link (cf. Baron 1997; Kennedy and Baron 1993), little is known about the victim/offender process. This paper formally addresses why some individuals are at higher risk for victimization compared to others; why some young people offend while others do not; and why those who are initially victimized are likely to retaliate based on an integrated theoretical interpretation using life course developmental theory and social interaction theory. Given that homeless young people generally have high rates of offending and are vulnerable to crime given their street exposure (Hagan and McCarthy 1997), they represent an ideal sample for examining this overlap and its process. The purpose of this investigation then was to examine, in depth, the experiences of victimization and offending among young homeless people and to place such experiences in a larger context by including an examination of both their early life histories and their current street exposure. Taken together, these two factors provide a better understanding of the offender/victimization process.

\section{Literature Review}

\section{Victimization}

Studies have shown that the prevalence of victimization among homeless youth is inordinately high with rates of sexual victimization, especially among women, often more than one-third (Janus et 
al. 1987; Silbert and Pines 1981; Tyler et al. 2001a) and physical victimization, such as assault and robbery, exceeding 50\% (Baron 1997; Kipke et al. 1997). Numerous risk factors contribute to the likelihood of victimization among homeless youth. For example, family abuse prior to running away has been found to be indirectly related to sexual victimization through a process of running away at earlier ages, associating with deviant peers and participating in deviant subsistence strategies and survival sex (Tyler et al. 2001b). There is also evidence that prior victimization is related to subsequent victimization experiences (Baron 1997) as is engaging in deviant behaviors (e.g., conning, stealing, trading sex) (Tyler et al. 2001a; Whitbeck and Hoyt 1999). According to these researchers, early abuse in the home places adolescents on trajectories for early independence. The coercive and abusive interaction styles learned in the home are generalized to other contexts whereby these youth are rejected by conventional peers, which leads to their involvement with delinquent peers, which is associated with victimization and offending. Other risk factors for victimization among homeless youth include alcohol and drug use (since youth are more apt to be careless and unaware of their surroundings while intoxicated and less able to defend themselves in a confrontation), (Baron 1997), "squatting" (sleeping in public places), and spending more time on the street (Hagan and McCarthy 1997).

\section{Offending}

Just as homeless youth experience high rates of victimization, they also often display a propensity toward offending. Much of this offending, however, may be viewed as basic survival strategies to generate money, goods, food, or drugs (Hagan and McCarthy 1997). Because many times homeless youth are too young, uneducated, and inexperienced to obtain legitimate employment (Administration on Children, Youth, and Families 1995; Gilfus 1992), many resort to shoplifting, robbery, selling drugs, prostitution, "dumpster diving," and panhandling (Whitbeck and Hoyt 1999). In other situations, criminal behavior is a violent response to the attempted victimization of themselves, their property, or their friends (Hagan and McCarthy 1997) thus suggesting a dyadic relationship between 
victimization and offending. Additionally, according to Kipke and associates, homeless youth are particularly vulnerable to violence, and being victimized or witnessing the victimization of others may lead them to perceive violence as a "normative response to conflict situations and use violence themselves as a means of resolving conflicts" (Kipke et al. 1997:367). This may be especially true for those who have been exposed to violence or abuse early on. According to Patterson (1982) this normative response may be attributed to the early coercive or abusive interaction styles that youth learned in their family of origin, which they are likely to generalize into other contexts including their interactions with others while on the street. Many homeless young people not only experience high rates of victimization but also display a propensity toward offending; thus, there is often a fine line between victimization and offending.

An integrated theoretical interpretation of the pathway into the victimization-offending process is proposed using life course developmental theory (Elder 1997) and social interaction theory (Patterson 1982). Although these two theories have roots in other traditions (e.g., learning theories, control theories), this paper focuses specifically on life course theory and social interaction theory due to their ability to explain how early life histories of these young people (e.g., conflict or abuse within the home) are associated with subsequent victimization, offending, and retaliation.

Patterson has argued that coercive families provide "basic training" for antisocial behavior (Patterson et al. 1984) such as offending. This "basic training" is the result of a continuous failure on the part of parents to use effective discipline techniques in controlling coercive exchanges between family members. Through this training, the child learns to control other members of the family by means of coercion (Patterson et al. 1984; Patterson et al. 1989). Adolescents who grow up in families that display aggressive and antisocial behavior are likely to be rejected by normal peer groups (Patterson et al. 1984), and thus associate with others who display similar characteristics (i.e., delinquent youth). These negative interaction styles become self-reinforcing over time resulting in the selection and creation of environments that are familiar and congruent with these interaction styles (Caspi et al. 1987). Thus, interactions within the family early on set the stage for the selection of certain peer groups, and 
associating with youth who have similar deviant interaction styles puts these young people on pathways that often lead to offending and victimization.

Once on this pathway, the social environment of the street in which young people interact further exacerbates the risk. Victimization theories (Cohen and Felson 1979; Hindelang et al. 1978), which define the social context in which crime occurs, are useful for explaining how the social environment in which homeless youth interact on a day-to-day basis puts them at risk for both victimization and offending. According to these theories, living on the streets exposes homeless youth to both criminals and potential victims and this increases the likelihood that some homeless youth may offend but also increases their chances of becoming victims. The offending-victimization process is such that early experiences with disorganized and abusive homes increase the potential that youth will come to associate with delinquent youth due to similarities in their interaction styles (e.g., antisocial behavior). This process is further exacerbated by the lifestyles and daily routines (e.g., spending time on the street late at night) engaged in by many of these young people, which put them in particular social environments where they are exposed to dangerous people and places that increase the likelihood for both victimization and offending.

\section{Method}

This investigation is based on data obtained from semi-structured interviews with 40 homeless youth (16 males; 24 females) as part of a larger longitudinal study. Young people were interviewed in four Midwestern states by street interviewers who were employed full time as survey researchers by the larger longitudinal project. Interviewers worked through the local service agencies to both collect data and serve as referral sources for services requested by young adults in crisis. This created greater access to youth and minimized the impression of an intrusive researcher. The shelters were chosen as part of the M.I.N.K consortium (Missouri, lowa, Nebraska, Kansas), which are the region's 7 service providers for youth in the Midwest. Interviewers were instructed to approach shelter residents and locate eligible respondents in areas of the cities where 
homeless youth congregate. Interviews were conducted in shelter interview rooms, apartments where youth were doubling up with friends or relatives, quiet corners of restaurants, and libraries. All interviewers had over two years of experience interviewing and interacting with homeless young people and were very familiar with local street cultures (e.g., knowing where young homeless people congregate and the kinds of services available to these youth). Study eligibility required young people to be between 19 and 21 years of age and homeless. The definition of "homeless" mandated that the youth currently resided in a shelter, on the street, or was living independently (e.g., with friends) because they had run away, had been pushed out, or had drifted out of their family of origin. Study procedures were explained and informed consent was obtained from youth.

The young people's reaction to this type of interviewing (i.e., open ended questions) was very positive. According to one interviewer, "It gave them a chance to be heard; that someone wanted to really hear what they had to say." Numerous youth expressed gratification with being able to sit down and think about their life and what they had been doing. According to another interviewer, "Many youth are so busy trying to survive that they do not think about the choices they are making day to day. The interviews seemed to help them reflect." Similarly, other young people indicated satisfaction with the interviews, which allowed them to provide specific details and to tell their side of the story with regard to family abuse and street experiences (i.e., victimization). Though some topics may have been difficult to discuss, overall, the response to the interview process was positive.

In terms of sample characteristics, the majority of young people were European American $(n=27), 8$ were non-Hispanic African American, 1 was Hispanic, and the remaining 4 self-identified as biracial or multiracial. Six youth had completed high school, 9 had completed their GED, 3 were still in high school, 5 were working on their GEDs, 12 youth had dropped out, and 5 individuals were not asked about their education level. The majority of the sample $(n=24)$ indicated that they did not currently work. Of those who did work, their employment included minimum paying jobs such as working at fast food restaurants or babysitting. 


\section{Coding and Theme Construction}

All interviews were audio taped and lasted 1 to $1 \frac{1}{2}$ hours on average. Participants were asked a series of open-ended questions, which focused on their family background and experiences on the street, including victimization (e.g., being beaten up, robbed, sexually assaulted) and criminal offending (e.g., robbing, conning, shoplifting, selling drugs, beating others up, sexually assaulting others). Each interview was transcribed verbatim. To preserve confidentiality, all names of respondents have been changed and names of stores and cities have been deleted from respondents' quotes. Respondents were paid $\$ 25$ for the interview.

The goal was to examine, in depth, the experiences of victimization and offending among young homeless people and to place such experiences in a larger context using an integration of pre-existing theories to explain the findings. Though the theoretical perspectives guided the interviewing and data collection process, the themes that were eventually generated emerged from the words of the respondents rather than from theory. Thus, rather than trying to force young peoples' experiences into preconceived categories, themes were allowed to evolve naturally (Charmaz 1995). After the interviews were transcribed, both authors carefully read through each interview and coded each incident as either victimization or criminal offending before comparing notes. During this process of open-ended coding, several themes began to emerge. Victimization behaviors came to be organized around financial gain and survival, paybacks, and exploitation while offending behaviors were organized around financial gain and survival, invulnerability, and paybacks. After these broad themes were identified, the process of focused coding begun (Charmaz 1995), which included searching the coded interviews for particularly telling excerpts and grouping them according to theme.

\section{Findings}

Offending behaviors are organized around three major themes that emerged from the process of open-ended coding. These include: (1) financial gain/survival strategies (e.g., stealing or scamming food, clothes, money), (2) invulnerability (e.g., portraying an image of 
strength and infallibility), and (3) paybacks (e.g., seeking revenge for an incident against them or a friend). Victimization themes included: (1) financial gain/survival strategies (e.g., being stolen from), (2) paybacks (being retaliated against), and (3) exploitation (e.g., being used or taken advantage of, perhaps sexually). All themes are important for explaining the victim/offender overlap.

In order to comprehend the process of victimization and offending that takes place on the street, it is important to be familiar with the early life histories of these youth. The majority of the sample (90\%) had experienced physical abuse and one third had experienced sexual abuse. A total of $33 \%$ of youth experienced both types of abuse. In addition to abuse, $93 \%$ of youth reported that a close relative (usually a mother and/or father) had substance abuse problems and $33 \%$ of youth said that their mother and/or father had engaged in criminal activity (selling drugs being the most common). Young people also left home for the first time at a very early age (Median=13 years). When asked why they left home for the first time, the majority of respondents indicated that it was some type of abuse, violence, and/or conflict that caused them to flee. This suggests that abusive and disorganized families are a major factor in young people's decision to leave home. In addition to not being adequately prepared for life on their own (i.e., with few resources and life skills), those who grew up with coercive families have likely learned antisocial behaviors (Patterson et al. 1984). Some of these young people learned to control other family members by means of coercion and then were likely to generalize these interaction styles into other contexts (e.g., using violence to control others on the streets) (Patterson et al. 1984; Patterson et al. 1989). Since youth are likely to select and create environments that are familiar and congruent with these interaction styles (Caspi et al. 1987), they will most likely "choose" delinquent youth as their peers and use coercion and revenge as a means to an end in their daily interactions. Further, given the high level of victimization that the majority of these young people have experienced prior to leaving home, they may come to view violence as acceptable behavior and are not only at risk of inflicting it upon others but also are at risk for becoming future victims themselves. 


\section{Offending Behaviors}

Financial Gain/Survival Strategies

The majority of criminal behaviors described by the respondents could be classified as offending for the purpose of survival and/or financial gain. Several of the youth reported stealing strictly for survival purposes. When asked how she got food, Vanessa replied, "I'II steal it if I have to because I mean I get hungry sometimes." She also indicated that she had stolen other items if she really needed them. Ryan justified stealing based on his living situation at the time. He reported that he was homeless and living underneath bridges so the only way he could get food and clothing was to steal it. Although stealing is criminal behavior, Vanessa and Ryan specified that they had engaged in theft strictly for survival purposes. Looked at within the current theoretical framework, their pathways into offending can be tied to their early histories of abuse and family disorganization, which were factors in their decisions to run away from home, thus placing them in the precarious position of being unable to support themselves.

Other youth described "scams" that they had used to obtain food or to obtain money to buy food. When asked how he got food, Greg explained a scam method that had worked well for him: "I'Il go to a grocery store and say the pop machine ate my dollari... so [I'll tell them] I put in another one [dollar] and say it ate that one too, so, like [I'Il get] two bucks and go buy some food." Similarly, when asked about how she obtained food, Carol described scamming fast food restaurants: "I would call fast food places and tell them I just came through and my order was wrong and they would fix it. That's how I get my food." Cindy describes a number of different tactics that she and her boyfriend had used while trying to survive on the streets:

If we wanted to eat, well nine times out of ten, I could write a bad check on my account. I mean, we were living on the streets, walking the streets all night long, cuz it was too cold to lay down anywhere and go to sleep. Going into 24-hour establishments, bumming money, telling people our car broke down and we needed to use the pay phone and so we got 
enough to get a soda. And just sat there all night, you know, getting free refills.

Other methods of offending for survival or financial gain described by the respondents included being given free food by friends employed at fast food restaurants and stealing merchandise to return it for cash refunds. Some reported engaging in scams for survival (i.e., they were starving and were desperate for food), whereas others reported participating in these activities for financial gain (i.e., as a way to make money to buy other goods). Many of these youth had been exposed to criminal activity in their family of origin and perhaps learned some of their scams from other family members. Given that their caretakers were often engaging in offending behavior, it is possible that some youth came to view this as a legitimate way to survive.

Hustling (i.e., strenuous efforts to obtain money using fraud and/ or deception) was another victimizing behavior that was reportedly used for survival and/or financial gain. Danny explained situations in which he found hustling necessary: "If I want a new pair of shoes I gotta get out and get some money somehow ... If I want a pack of cigarettes I gotta get out and get five dollars somehow." John spoke of panhandling for money while he was on the streets as a way to survive. He did so outside of fast food restaurants, drug stores, or in the downtown area, typically targeting business people. Scott also spoke about "spanging" (asking for spare change). He claimed that on a good day during the summer, he could make over $\$ 50$.

Selling drugs was another common method that youth used for financial gain. One male youth reasoned that he could either make $\$ 40$ a day at a minimum wage job or make $\$ 150$ a day selling drugs. There was not any question in his mind as to which path to choose. This finding echoes those of Hagan and McCarthy (1997) who reported that non-criminal means of survival often do not compare to what can be obtained through criminal means.

The high rate of drug activity among youth is not surprising given their family histories of criminal involvement in selling and/or using drugs. As such, many of these youth had grown up in or had at least been exposed to a drug environment while still living at home and 
thus may view drug sales as an acceptable way to earn a living or "make a quick buck."

Invulnerability

The necessity to portray an image of invincibility was the second theme that emerged under offending behavior. Convincing others that one is strong, infallible, and not afraid of anything (see also Miller 1958) is the only way to survive on the streets according to many youth. Julia, who was in a gang, indicated that an image of invincibility was necessary in order to survive. She advised, "Definitely make sure you're top dog. If it means you hurt people before they hurt you, you do it." Many youth, both males and females, were involved in street fights or reported having beaten someone up. Often fights involved numerous people, were reciprocal, and in some cases were gang related. Whether youth started the fights or were defending themselves, it was imperative that they gave the appearance of invulnerability. As one youth put it:

You can't be afraid because ... living on the streets, being afraid will kill you. If you're living on the streets that much, a bunch of vultures, that's how you think about it ... looking scared looking like you don't know where you're going, you're gonna get took in a heartbeat.

Given that almost all youth in the sample grew up in physically violent households, many may have learned that fighting is a way to solve problems or get what they want. According to Patterson and colleagues (1984), this type of interaction style is then likely to be used in other peer interactions. Therefore, the violence and antisocial behavior that these youth learned at home is carried with them onto the street. Portraying an image of invincibility is perhaps first a way to survive at home, and then later used as a tool for surviving on the street.

\section{Paybacks}

The final theme that emerged under offending behaviors was that of paybacks. Within the context of retaliation, victims may seek revenge for previous victimization of themselves or their friends. Randy explained how he got revenge for a female friend: "We knew 
a girl at one point and time that some guys had tried to rape and about five of us had gotten together and we went and just beat the hell out of him for it." In another example, Danny was approached by a peer and robbed. The offender had a gun and threatened to kill Danny if he did not give him the marijuana he was carrying. Danny complied knowing that he would retaliate against this individual at a later date. He reported having thought, "Hey, you can have the 20-sack buddy. I'Il catch you another time." Three weeks later, Danny coincidentally ran into this same youth at a club and beat him up. When asked why, he stated, "Because he robbed me. Took my 20 sack. He made me feel like a girl man ... I felt all defenseless and shit." If Danny did not get even, he may be at risk for future assaults. According to Topalli and colleagues (2002), "criminal victims" are left to their own devices and direct retaliation is the best measure of justice. That is, "The shame, embarrassment and humiliation associated with being robbed create in many victims ... a strong motivation to satisfy angry feelings by restoring a sense of reciprocal balance or, in everyday language, by 'getting even'" (Topalli et al. 2002:340).

The need for revenge is strong among youth currently engaging in criminal behavior. Jody, a drug dealer, felt taken advantage of when a customer refused to pay for his drugs. Jody wanted to get revenge and asked a friend to help him do so. He explained:

Well, one time me and my friend gave this dude a half-ounce it was like $\$ 140$ [and] he decided not to pay. So we [later went to this man's apartment and] broke the window and got his TV [and] sold his TV for \$140. (Laughs) ... Swift justice that's all.

Jody's description fits well with Black's (1983) crime of self-help whereby Jody was determined to seek justice and take the law into his own hands. Additionally, it is possible that Jody's involvement in offending stems from his early family history, which included parental drug use, criminal activity, and a physically violent household. Further, Jody's retaliation may be linked to the abusive and coercive interaction styles that he may have learned from his parents. This "basic training" for antisocial behavior is likely to be 
generalized into other contexts including Jody's current interactions with street youth and other people.

As these stories indicate, youth engage in numerous offenses, some for financial gain or survival purposes, others as a way of payback or revenge, and still others as a means of portraying an image of invincibility. Given the family environments in which the majority of these youth grew up, it is not surprising that many of them have sought out situations in which others are coercive and/or antisocial since these are the types of interaction styles to which they have become accustomed (Caspi et al. 1987; Patterson et al. 1984).

\section{Victimization}

Because the perpetrators against homeless youth were not interviewed, the motives behind their victimizing behaviors are unknown. Therefore, what is reported here is based on the victim's perceptions of the perpetrator's motives. The victimization themes that emerged included exploitation, paybacks, and financial gain.

\section{Exploitation}

Boyfriends perpetrated the majority of victimizations that women experienced. Some young women indicated that their boyfriends or other men were coercive, always had to be in control, and had used them for sex, pleasure, or financial gain. These experiences were placed under the theme of exploitation. Jackie explained being sexually assaulted by a man who she said gave young women a place to stay but often got them drunk and took advantage of them sexually. Jackie reported being sexually assaulted and raped a total of three times since being on the street. Another sexual assault victim, Stacey, was exploited by her boyfriend who first got her hooked on crack and then coerced her into selling her body for money so he could buy more drugs. Another young woman, Candy, explained how she was threatened and raped by an acquaintance who then robbed her, taking her money and her identification. Candy described another situation in which her son's father "would make her" spend money on him that, according to her, needed to be spent on her son. All of the above scenarios depict the exploitation of these young women; some were used for sex, 
some were used to generate drug money, and some were used for financial gain. In all of these contexts, men had used these women for their own personal gain.

Given that all of these young women had experienced some form of abuse prior to leaving home, they were at higher risk for re-victimization. That is, having been exposed to coercive and/or abusive parenting, they are likely to have learned similar interaction styles, to have thus been rejected by normal peer groups, and therefore to have associated with individuals who display similar characteristics (i.e., highly coercive and abusive interaction styles) (Patterson et al. 1984). Continued exposure to violence and abuse in the home works to lower adolescents' self-esteem and conveys to them that they are worthless and that they did something to "deserve" their punishment. This is carried over into other interactions and relationships outside the family. Young people continue to believe that they must have done something to "deserve" their punishment (e.g., exploitation by a boyfriend) and that such interaction styles are "normal"; they therefore, become accepting or at least tolerant of the violence. As such, they are likely to continue to be at high risk for victimization unless some intervention is introduced.

One young male respondent reported being in a situation in which young women tried to sexually exploit him. Even though Brian joked about it, the incident does constitute sexual exploitation. Brian stated: "They [two women] started flirting with me, wrestling with me, trying to pull my pants down." In other words, the women were using Brian for their own sexual pleasure. This is an interesting situation and the context is important here. If this was a woman in the same situation and two men were trying to pull down her pants, it would immediately be labeled as sexual assault. Because it was a man, however, it is easier to dismiss this episode as just "playing around."

Although one young man had experienced sexual exploitation, it appeared that males were not typically exploited in this way, as was the case for women, but rather were often used as "tools" for improving the image of other men. Because respect and an image of invincibility are crucial to survival on the streets according to youth, the struggle for the acquisition of these traits is acute and ongoing. Some young men described in detail the physical victimization that 
they had experienced. Michael described an incident in which someone tried to stab him while he was staying at a homeless shelter. Brian explained a similar harrowing experience: "They'd push me around, get up in my face, start threatening me, telling me how they were going to kill me and beat me up, you know." In yet another battle for respect, Michael reports being severely beaten by six men. Through this altercation, the other men (who "won" the battle) undoubtedly had their images of invincibility strengthened by their triumph, while Michael (who was on the losing end) had his image weakened. Through physical assault and victimizing behavior, other street youth were able to protect and/or build their images of invincibility at the expense of the current respondents. Michael and Brian, who were both victims of physical abuse prior to leaving home, once again experienced what it feels like to be a victim. Earlier family interactions, patterns of abuse, and/or coercion may result in these young people learning the role of victim, which is likely generalized into future situations.

\section{Paybacks}

Some youth experienced victimization in the form of paybacks. Cindy, who was physically assaulted by her boyfriend on numerous occasions and who often fought back, described how her boyfriend would retaliate instantly against her:

I mean, he [boyfriend] was violent, you know, he hit me and kicked me and pulled my hair, choked me, all of that fun stuff. And I did it right back. ... [then] we got into it again, [and] he broke my nose again right after I had gotten it set.

Brian also discussed "immediate paybacks" that were linked to fights that he had had. In one case, Brian reported engaging in assault (i.e., offending) in order to get revenge for a prior incident, but became the "victim" as another youth subsequently sought revenge on him. Brian noted: "There were two dudes that were kicking me. I got up and I started socking kids in the face. They all ran off but one came running back with a lead pole and chasing me and hitting me with it in the back." This vignette reveals the complexity of the victim/offender relationship; Brian was attempting to seek revenge for an earlier incident targeted against his friend but instead, 
Brian got beat up, retaliated on the spot, and then was attacked by these same youth.

Brian and Cindy both came from physically violent households and according to social interaction theory, they are likely to seek social groups that reinforce the behaviors that they learned in their family of origin (Patterson et al. 1984). Given that both youth likely learned to respond to difficult and/or threatening situations by using force and/or other antisocial behaviors, their early life histories explain not only their participation in deviant social groups, but also why these youth are likely to seek revenge (and hence become offenders) as well as why they are at risk for future re-victimization.

Financial gain

Although the perpetrator's motives are again unknown, according to the following victims the crimes against them were motivated by a quest for financial gain. Several youth described how they had stolen from others because they needed money or were hungry (i.e., offending behaviors), but few youth described in great detail what others had stolen from them (i.e., victimization experiences). Perhaps the reluctance to discuss these victimization experiences in detail is due to the image of invincibility that the youth wish to portray. Admitting to being robbed suggests that one can be easily taken advantage of and is an easy target. This may be especially true when the victims know their assailants as was the case for the youth described below.

Stacey, who was living with her ex-boyfriend's uncle, explained how she had been a victim of theft perpetrated by her ex-boyfriend:

I guess one time last week I wasn't there and he [ex] came up in the house and ... my keys was up in my room. He [ex] came and took my keys and I had this friend bring me some food back because I didn't have no money and I didn't have no food stamps so I told this guy to bring me some food by and he brought it by and my uncle put it up in my room and he [ex] took my keys and my food.

This was very stressful for Stacey given that she lacked money to buy more food and would now go hungry. Additionally, her boy- 
friend stealing her keys left her vulnerable to future victimization since she was then unable to lock her room.

Kurt also admitted to being a victim of robbery perpetrated by his best friend who was also his roommate. When asked to explain, Kurt indicated that the episode was something he did not like to think about. It is likely that the incident damaged Kurt's image of invincibility and that he felt betrayed by his best friend. Vanessa was also robbed by one of her friends. She explained:

It's not like [they] snatched my purse or anything but someone picked through my purse and took my money. I had, like, seventy dollars a couple of weeks ago and somebody took it out of my purse while I went to use the bathroom.

When asked if she knew who took it, Vanessa replied, "I have my suspicions." She was staying at a friend's house at the time and reasoned that it was one of them. Due to their early family histories, some of these youth are likely to engage in antisocial behavior, which results in their association with delinquent youth (Patterson et al. 1984). As a result of these associations, study youth are likely to be at higher risk for various types of victimization.

\section{Victim/Offender Link}

Thus far, the themes underlying offending behaviors and victimization experiences have been discussed. Given that 25 youth (63\%) who had engaged in criminal behavior had also experienced victimization, the specific overlap between these two groups warranted a closer look. That is, why are some individuals at higher risk for victimization compared to others?; why do some young people offend while others do not?; and why are criminal victims likely to retaliate? The proposed integrated theory can be used as a framework for systematically addressing these questions within the context of the respondents' life histories and daily lived experiences. Youth who conned and stole on a regular basis for financial gain were aware of the possibility that they could encounter some of their previous victims, thereby placing them at risk of being retaliated against and thus becoming victims themselves. Sa- 
mantha's con game included stealing cars and selling stolen items on the street or to pawn shops. She reports having to evade her former "victims" for fear of retribution. Samantha was aware that she was in danger and that the tables could easily be turned on her. To specifically address the first research question then, why Samantha was at higher risk for victimization compared to others can be explained by the fact that she was engaging in offending behaviors that were likely to instigate retaliation. Another youth, Mary, also was aware of the risks involved regarding offending for financial gain and was conscious of the fact that the roles of victim and offender may quickly become reversed. Mary, who was often out on the street selling drugs (i.e., offending), acknowledged the possibility of being attacked and/or robbed at gunpoint (i.e., victimized). Being out on the streets late at night and engaging in criminal behaviors (e.g., selling drugs) is a dangerous enterprise and may lead to increased victimization risks. Mary described being robbed at gunpoint while selling drugs at 2 a.m. one morning. She explained that a man came out of nowhere, held a gun to her head, and threatened to shoot her unless she gave him everything she had. Mary reported that shortly after the incident she was hesitant about standing on a corner selling drugs however; she has since mitigated her fear by carrying a large knife for protection in the event that she is robbed again. Thus, to once again address the first research question, Mary was at higher risk for victimization compared to others because she spent time in dangerous places interacting with dangerous people (i.e., other criminals). Both Mary's and Samantha's situations are consistent with a victim precipitation model. Gottfredson (1981) pointed out that the actions of a potential victim can play a role in the likelihood of their victimization (see also Wolfgang 1957). Therefore, given that both of these youth often found themselves in high-risk situations because of their own actions, this likely influenced their subsequent risk of victimization.

Of the seven young women who were victimized by their boyfriends, all of them were also involved in offending such as theft and shoplifting, selling drugs, stealing vehicles, or using stolen checks. For some of the young men who had been robbed or beaten up, they also admitted to shoplifting, robbing, coercing others to buy 
drugs, and being physically violent toward others. Although there is a connection between engaging in offending behaviors and being victimized, only about half of the sampled youth appeared to recognize the connection. As indicated previously, Mary, who sold drugs, was aware that someone might come up behind her with a weapon and rob her, turning her, the offender, into the victim. Other young women who were involved in stealing and conning (often due to exploitation by their abusive boyfriends) did not appear to recognize this link. An alternative explanation is that these women may have been aware of the link, but felt as though they had no other viable options; thus they continued to offend. Many of the young men likely recognized the offender/victim link as well but were forced to "defend their honor" if someone took advantage of them on the street, even if it meant offending or being victimized. As many young men attested to, it is dangerous to show fear because potential offenders are likely to interpret this fear as an opportunity for victimization.

There also was a strong connection between having been a victim of abuse prior to leaving home and being re-victimized or victimizing others out on the street. This pattern was similar for both males and females suggesting that adolescents who grow up in families that display aggressive, coercive, and abusive behavior are likely to learn similar interaction styles and generalize them into other contexts (Patterson et al. 1984) by selecting friends and creating environments that are congruent with their learned antisocial behavior. Selecting delinquent youth as friends increases these young people's chances of offending as well as becoming victims. Moreover, the social context of the street environment is likely to exacerbate the risk. That is, by spending a lot of time on the street, especially at night, young people are exposed to potential offenders as well as potential victims. This not only increases their risk for subsequent victimization but it also increases the chance that they will victimize others in the course of their interactions. In line with this, the first two research questions, why some individuals are at higher risk for victimization than others and why some young people offend while others do not, can be more clearly addressed by examining the early life histories of the respondents. One possible answer is that youth who are exposed to violence and coercive behavior at home are likely to 
model this behavior on the streets and seek out other youth who exhibit the same traits.

The third and final research question, why criminal victims are likely to retaliate, can be addressed by once again examining the early life histories and daily lived experiences of the respondents. Brian explained that he was robbed at gunpoint. As the story below unfolds, notice the context of the situation, which exemplifies the victim/offender link quite well. This vignette demonstrates how the role of offender and victim can be reversed:

A couple months ago, I was attempting to purchase something but I wasn't there at the time. I had sent somebody else to do it and they came back with no money and no product. I was really mad so I went to the house and they pulled a gun on me. I didn't really feel like testing faith in case he would pull the trigger. I had to let it go and me and my roommate got screwed out of the deal.

In this situation, Brian set out with the intent of retaliating (i.e., being the offender), but the tables were turned and he quickly became the victim (cf. Wolfgang 1957). Given the angry state that Brian was in when he left, he is likely to lodge a payback in the near future, and the cycle continues. Within the context of this situation, the question of why criminal victims retaliate can be understood. Brian's abusive childhood can be seen as "basic training" for antisocial behavior, which may translate to later acts of violence and offending. As a result, he is likely to respond to conflict with violence. Further, given that Brian is a criminal himself, he is unlikely to enlist the help of authorities in his quest for justice.

\section{Summary}

In the above analysis, an integrated theoretical interpretation of the pathway into the victimization-offending process using life course theory (Elder 1997) and social interaction theory (Patterson 1982) was proposed. Three research questions were addressed within this theoretical framework: Why are some individuals at higher risk for victimization compared to others?; why do some young people offend while others do not?; and finally, why are criminal victims likely 
to retaliate? According to the integrated model, interaction styles learned at home are reinforced over time as youth seek out relationships with other deviant youth (Caspi et al. 1987; Patterson et al. 1984) who are often antisocial, coercive, and even abusive. Though these are interaction styles that many youth understand given their early family histories, such interactions are likely to increase their chances of offending, being at risk for re-victimization, as well as engaging in acts of retaliation. Not only do many of the study youth exhibit antisocial behavior, but the context of the street environment, which includes regularly spending time on the street, often late at night, is also important since it exposes these youth to potential offenders and/or victims.

\section{References}

Administration on Children, Youth, and Families. 1995. Youth with Runaway, Throwaway, and Homeless Experiences: Prevalence, Drug Use, and Other At-Risk Behaviors. Research Triangle Park, NC: Research Triangle Institute.

Baron, Stephen W. 1997. "Risky Lifestyles and the Link Between Offending and Victimization." Studies of Crime and Crime Prevention 6:53-71.

Baron, Stephan W. and Leslie W. Kennedy. 1998. "Deterrence and Homeless Male Street Youths." Canadian Journal of Criminology 40:27-60.

Black, Donald. 1983. "Crime as Social Control." American Sociological Review 48:34-45.

Caspi, Avshalom, Glen H. Elder, and Daryl J. Bem. 1987. "Moving Against the World: Life-Course Patterns of Explosive Children." Developmental Psychology 23:308-13.

Charmaz, Kathy. 1995. "Grounded Theory." Pp. 27-49 in Rethinking Methods in Psychology, edited by J. A. Smith, R. Harre', and L. V. Langenhove. Thousand Oaks, CA: Sage.

Cohen, Lawrence E. and Marcus Felson. 1979. "Social Change and Crime Rate Trends: A Routine Activity Approach." American Sociological Review 44:588-608.

Elder, Glen. 1997. "Life Course and Human Development." Pp. 939-91 in Handbook of Child Psychology, Volume 1: Theoretical Models of Human Development, edited by R. Lerner. New York: Wiley. 
Gary, Faye A. and Doris Williams Campbell. 1998. "The Struggles of Runaway Youth: Violence and Abuse." Pp. 156-73 in Empowering Survivors of Abuse: Health Care for Battered Women and Their Children, edited by J. C. Campbell. Thousand Oaks, CA: Sage.

Gilfus, Mary E. 1992. "From Victims to Offenders: Women's Routes of Entry and Immersion into Street Crime." Women \& Criminal Justice 4:63-89.

Gottfredson, Michael R. 1981. "On the Etiology of Criminal Victimization." The Journal of Criminal Law and Criminology 72:714-26.

Hagan, John and Bill McCarthy. 1997. Mean Streets: Youth Crime and Homelessness. New York: Cambridge University Press.

Hindelang, Michael, Michael Gottfredson, and James Garofalo. 1978. Victims of Personal Crime: An Empirical Foundation for a Theory of Victimization. Cambridge: Ballinger.

Janus, Mark-David, Arlene McCormack, Ann Wolbert Burgess, and Carol Hartman. 1987. Adolescent Runaways: Causes and Consequences. Lexington, MA: Lexington Press.

Kennedy, Leslie W. and Stephen W. Baron. 1993. "Routine Activities and a Subculture of Violence: A Study of Violence on the Street." Journal of Research in Crime and Delinquency 30:88-112.

Kipke, Michele D., Thomas R. Simon, Susanne B. Montgomery, Jennifer B. Unger, and Ellen F. Iverson. 1997. "Homeless Youth and their Exposure to and Involvement in Violence While Living on the Streets." Journal of Adolescent Health 20:360-67.

Lauritsen, Janet L., Robert J. Sampson, and John H. Laub. 1991. "The Link Between Offending and Victimization Among Adolescents." Criminology 29:265-91.

McCarthy, Bill and John Hagan. 1991. "Homelessness: A Criminogenic Situation?" British Journal of Criminology 31:393-410.

Miller, Walter B. 1958. "Lower Class Culture as a Generating Milieu of Gang Delinquency." Journal of Social Issues 14:5-19.

Patterson,Gerald R. 1982. Coercive Family Processes. Eugene, OR: Castilia.

Patterson, Gerald R., Barbara D. DeBaryshe, and Elizabeth Ramsey. 1989. "A Developmental Perspective on Antisocial Behavior." American Psychologist 44:329-35.

Patterson, Gerald R., Thomas J. Dishion, and L. Bank. 1984. "Family Interaction: A Process Model of Deviancy Training." Aggressive Behavior 10:253-67.

Silbert, Mimi H. and Ayala M. Pines. 1981. "Sexual Child Abuse as an Antecedent to Prostitution." Child Abuse \& Neglect 5:407-11. 
Topalli, Volkan, Richard Wright, and Robert Fornango. 2002. "Drug Dealers, Robbery and Retaliation: Vulnerability, Deterrence and the Contagion of Violence." British Journal of Criminology 42:337-51.

Tyler, Kimberly A., Dan R. Hoyt, Les B. Whitbeck, and Ana Mari Cauce. 2001a. "The Effects of High-Risk Environment on the Sexual Victimization of Homeless and Runaway Youth." Violence and Victims 16:441-55.

Tyler, Kimberly A., Dan R. Hoyt, Les B. Whitbeck, and Ana Mari Cauce. 2001b. "The Impact of Childhood Sexual Abuse on Later Sexual Victimization Among Runaway Youth." Journal of Research on Adolescence 11:151-76.

Whitbeck, Les B. and Dan R. Hoyt. 1999. Nowhere to Grow: Homeless and Runaway Adolescents and Their Families. New York: Aldine De Gruyter.

Wolfgang, Marvin E. 1957. "Victim-Precipitated Criminal Homicide." Journal of Criminal Law and Criminology 48:1-11. 